Pecvnia, 7 (2008), pp. 45-71

\title{
Nuevos tiempos para el movimiento sindical: balance y retos a comienzos del siglo XXI
}

\author{
Roberto Fernández Fernández \\ rferf@unileon.es \\ Universidad de León \\ Área de Derecho del Trabajo y de la Seguridad Social \\ Fac. de Derecho \\ Recibido: Octubre 2008 \\ Campus de Vegazana, $\mathrm{s} / \mathrm{n}$ \\ Aceptado: Mayo 2009 \\ 24071 León (España)
}

Las transformaciones operadas en las relaciones colectivas de trabajo no sólo obstaculizan la agrupación de los trabajadores en torno a unos intereses comunes, sino que implican la aparición de modernos escenarios en los cuales habrá de desarrollarse la acción colectiva y en cuyo seno los marcos de actuación aparecen conformados de forma más difusa, tal y como ocurre en los grupos de empresa, sectores descentralizados o empresas auxiliares.

De esta manera, los sindicatos deben asumir como propios nuevos retos destinados a adaptar su organización a la coyuntura actual y satisfacer las heterogéneas necesidades de los distintos grupos presentes en el mercado laboral, ofreciendo soluciones frente a las siguientes circunstancias: ganar una dimensión supranacional para estar presentes
The transformations in the collective labour relations, as well as obstruct the workers' union round their joint interests, also imply the appearance of modern contexts where the collective action has to operate; and in whose interior the frameworks of actuation appears in more blurred ways.

So, the trade unions have to take on like own new challenges aimed to adapt their organization to the current situation and to satisfy heterogeneous necessities, offering solutions to the next circumstances to gain a global dimension, with the objective of be present in certain international headquarters (to take part in the improvement of living and working conditions); to remedy the low affiliation rates characteristic of the Spanish model, 
en determinadas instancias internacionales que les permitan participar en una mejora de las condiciones de vida y laborales de los trabajadores; poner remedio a la escasa afiliación sindical presente en el modelo español, superando la resistencia que un buen número de trabajadores han mostrado hacia la representación obrera; en fin, analizar el modelo de representatividad sindical español, que al girar en torno al procedimiento electoral ha fortalecido la posición de los sindicatos más representativos, quienes, al controlar su convocatoria, pueden gobernar tranquilamente el proceso y esperar unos resultados capaces de preservar el panorama actual.

Palabras clave: Sindicalismo, globalización, escasa afiliación, representatividad, segmentación del trabajo. getting over the traditional working-class resistance to the labour representation; well, to analyse the Spanish model, which, on the basis of an electoral method, has strengthened the position of the most representative unions, which, since control its call, can govern quietly the process and expect to preserve the nowadays panorama.

Key words: Trade unionism, globalization, poor union membership density, representativeness, labour segmentation.

Los sindicatos han sido tradicionalmente definidos como

unas:

asociaciones para el progreso económico y social de sus miembros, especialmente para el mantenimiento y mejora de sus condiciones de trabajo a través de la negociación colectiva [y cuya] finalidad [cabe situar] en la de mantener y mejorar las condiciones de vida de sus miembros, siendo éstos precisamente trabajadores por cuenta ajena ${ }^{1}$.

A partir de semejante definición, han presentado como rasgos característicos los siguientes: subjetivo, pues se trata de una organización constituida e integrada, fundamentalmente, por trabajadores; funcional, en tanto creado para la autotutela colectiva de los intereses generales de éstos, frente a los contrapuestos del capital; organizativo, al ser una asociación, en cuanto unión estable y permanente de empleados, de manera que en cuanto universitas personarum, posee un conjunto de bienes y derechos para el cumplimiento de sus fines, está dotado de capacidad jurídica y de obrar que garantiza su autonomía; en fin, carencia de ánimo de lucro².

M. Alonso Olea (1955 y 2000) Pactos colectivos y contratos de grupo. Madrid: Gráficas González y Granada, Comares, p. 31 y 19, respectivamente.

2 Por todos, M.C. Palomeque López (1986) Derecho Sindical español. Madrid: Tecnos, pp. 37-41 y J.J. Fernández Domínguez, M.R. Martínez Barroso y S. Rodríguez Escanciano (1998) El Derecho del Trabajo tras las últimas reformas "flexibilizadoras" de la relación laboral. Madrid: CGPJ, p. 148 y 149, nota 352. 
Sin embargo, las nuevas coordenadas bajo las cuales se desarrollan las relaciones laborales en el siglo XXI les fuerzan a asumir nuevos retos destinados a adaptar su organización a la coyuntura actual, pues no cabe obviar las consecuencias que en su funcionamiento ha causado el fenómeno de:

la desagregación, con el correlativo desplazamiento del centro de gravedad de la debilidad socio-económica desde el mundo del trabajo asalariado al de la marginación y exclusión, [y que] "viene marcada por las exigencias de una mayor apertura hacia la atención de nuevas dimensiones sociales e incorporación de los nuevos movimientos", todo ello en el marco de la pretendida construcción de los "derechos de la ciudadanía" y de una búsqueda constante de consenso y cohesión ${ }^{3}$.

Por tales motivos, los sindicatos deben identificar cuáles van a ser los campos de batalla del nuevo siglo y las armas a utilizar para seguir luchando por defender los derechos logrados, extenderlos a nuevos trabajadores y mejorarlos; la necesaria adaptación resulta más acuciante en un momento como el actual donde las recetas prescritas para superar las dificultades económicas son totalmente contradictorias pues algunos solicitan sustanciales reformas del mercado de trabajo, adoptando medidas de flexibilización que permitan a las empresas adaptarse a los nuevos tiempos sin el corsé de una regulación tan rígida, mientras otros no están dispuestos a sacrificar las prerrogativas ganadas tras duros años de reivindicaciones y dudan de la virtualidad práctica de un aumento de los poderes empresariales. Además, conviene tener presente, y los hechos parecen estar dando la razón a quien realizó la afirmación, como:

una de las características del mercado laboral español es su elevada sensibilidad al ciclo económico... circunstancia que en la [anterior] etapa expansiva se ha traducido en una intensa creación de empleo, supondrá unos ritmos

\footnotetext{
3 M.E. Casas Baamonde (1999) "Nuevas tendencias de la negociación colectiva en Europa", Empleo, contratación y negociación colectiva. XI Jornadas de Estudio sobre la Negociación Colectiva. Madrid: MTAS, p. 78 y (1997) "Las transformaciones del trabajo y de las relaciones colectivas", Relaciones Laborales, 23, p. 4. De la misma opinión, S. Rodríguez Escanciano (2002) "Nuevos marcos para la acción colectiva: la implantación de un sistema de relaciones laborales más dinámico y participativo", Revista de Trabajo y Seguridad Social (Centro de Estudios Financieros), 235, p. 28.
} 
acentuados de destrucción del mismo cuando cambie el signo de ciclo ${ }^{4}$.

En consecuencia, los cauces y fórmulas de representación y participación de los sindicatos cobran un protagonismo renovado y han de hacer frente a retos parcialmente distintos en el ejercicio de sus funciones.

Así, habrán de encontrar solución para antiguos problemas como la crisis en la representatividad, la institucionalización o la deficiente afiliación y hacer frente a novedosas circunstancias como la globalización del mercado y la cada vez mayor heterogeneidad de los grupos de empleados con diversos intereses e inquietudes; todos estos frentes abiertos les exigen, a la postre, una mayor implicación y conexión con el sentir y sustrato social al cual representan.

\section{EL SINDICATO ANTE EL FENÓMENO DE LA GLOBALIZACIÓN}

En un mundo global, el sindicato debe construir su espacio de actuación más allá de las fronteras internas, ganar una dimensión supranacional, pues numerosas decisiones económicas están siendo, y cada vez en mayor número -baste para ello repasar la prensa general y económica de los últimos meses a fin de corroborar tal realidad-, adoptadas en este nivel, lo cual exige elaborar políticas de actuación socio-económica en un ámbito superior al estatal ${ }^{5}$.

Precisamente la globalización acaba siendo otro de los campos de batalla del sindicalismo actual, quizá el más importante, en tanto resalta los elementos más críticos e introduce la dimensión mundial como escenario muchas veces exasperante de los intereses contrapuestos en el interior de la fuerza de trabajo ${ }^{6}$, haciendo más notoria la propia crisis de su función de representación a escala universal ${ }^{7}$. Resulta necesario,

\footnotetext{
J.V. Pitxer i Campos y A. Sánchez Velasco (2008) "Estrategias sindicales y modelo económico español", Cuadernos de Relaciones Laborales, 26, núm. 1, p. 93 y 94.

5 R. Sastre Ibarreche (2003) "Algunas claves para un sindicalismo también mundializado", Revista de Derecho Social, 21, p. 70.

6 H. Álvarez Cuesta (2006) La mayor representatividad. León: Universidad de León, p. 169 y ss.

A. Baylos Grau (2001) "Representación y representatividad sindical en la globalización", Cuadernos de Relaciones Laborales, 19, p. 74 y D. Lantarón Barquín (2000) "Reflexiones en torno al devenir del sindicato y a los factores que influyen en su evolución: ¿crisis y/o metamorfosis?", Revista de Derecho Social, 10, p. 72.
} 
por tanto, "normalizar en estos terrenos la presencia de la acción sindical, reformulando las relaciones de poder en los mismos de forma no asimétrica, y estableciendo 'contrapesos' en las mismas"8.

Las organizaciones obreras se enfrentan así a la necesidad de reorientar su actividad y reordenar su estructura interna ${ }^{9}$ con el fin de adaptarse a esta moderna situación;

deben asumir nuevas responsabilidades y competencias que se salen del marco tradicional de la empresa, en un extremo, y del Estado nacional, en el otro, para adquirir una dimensión regional y sociopolítica, abierta a la colaboración con otras agrupaciones sociales y capaz de establecer mecanismos eficaces de intervención a escala internacional ${ }^{10}$.

En este sentido, han de superar el marco estatal a fin de ceder parte de su "soberanía" en beneficio de organizaciones de carácter internacional ${ }^{11}$, tal y como ya se ha ensayado con la Confederación Europea de Sindicatos, cuya actuación a nivel comunitario ha permitido ganar espacios antes desconocidos.

Los sindicatos han de esforzarse por generar un mensaje tendente a abrir espacios de convivencia democrática que permitan recuperar la confianza de los trabajadores en torno a la posibilidad de construir un futuro basado en la justicia y la igualdad ${ }^{12}$, pues la eficacia en la actuación va a depender de su capacidad para complementar la acción empresarial y nacional con la actividad y la presión en el ámbito

8 A. Baylos Grau (1999) "Globalización y Derecho del Trabajo: Realidad y proyecto", Cuadernos de Relaciones Laborales, 15, p. 46 y 47.

9 J.R. Mercader Uguina (2003) "Sistema de fuentes y globalización", Revista Española de Derecho del Trabajo, 119, p. 681.

10 S. Rodríguez Escanciano (2002) "Nuevos marcos para la acción colectiva: la implantación de un sistema de relaciones laborales más dinámico y participativo", ed. cit., p. 58 , remitiendo a J.I. Palacio Morena (1993) "Prólogo", D. Albers, et al.: La política regional de los sindicatos europeos. Un análisis comparativo. Madrid: MTSS, p. 21.

11 M. D'Antona (1998) "Contrattazione collettiva e concertazione nella formazione del diritto sociale europeo", A. Lettieri y U. Romagnoli (dirs.) La contrattazione collecttiva in Europa. Roma: Ediesse, p. 113.

12 C. de la Serna Arenillas (2003) "Retos sindicales ante el siglo XXI", Revista de la Asociación Estatal de Centros Universitarios de Relaciones Laborales y Ciencias del Trabajo, 12, p. 155. 
político internacional ${ }^{13}$. La tarea, se reconoce, no va a resultar fácil ${ }^{14}$ y el mayor problema dentro de esta esfera radica en la legitimación o representatividad obrera, es decir, conformar su capacidad para construir amplios consensos en el marco de su acción, de tal manera que la cuestión a dilucidar radica en la posibilidad de

mantener una situación de pluralismo real en la expresión del interés de todos los trabajadores de los distintos territorios que componen el nuevo espacio integrado económica y monetariamente a nivel supranacional, y si la síntesis de ese interés global de los trabajadores la puede realizar convincentemente el sindicato ${ }^{15}$.

\section{UN PROBLEMA CON TINTES DE PANDEMIA: LA ESCASA AFILIACIÓN SINDICAL}

Cabe esbozar brevemente una de las dificultades dentro del panorama sindical español, configurada ya como endémica, a situar en el escaso índice de afiliación padecido por las asociaciones obreras ${ }^{16}$, capaz de calificar al sistema nacional como "sindicatos sin sindicados" o "sindicalismo sin sindicalistas"17.

Las causas que originan esta debilidad afiliativa son muchas ${ }^{18}$, y sin pretender entrar a enumerar todas ellas pues dicha labor excedería

13 C. Prieto Rodríguez (2001) "Trabajo y globalización económica", Globalización, trabajo y movimiento sindical, Madrid: Fundación Paz y Solidaridad, p. 51.

14 Un análisis detallado sobre las dificultades y retos de la acción sindical internacional frente a la globalización, en J.M. Antenas Collderram (2008) "Los sindicatos ante la globalización. ¿Hacia qué nuevas formas de solidaridad internacional?", Cuadernos de Relaciones Laborales, 26, núm. 1, pp. 46-51.

ed. cit., p. 41 .

15 A. Baylos Grau (1999) "Globalización y Derecho del Trabajo: Realidad y proyecto",

16 Un estudio reciente sobre los índices de afiliación en España y su contraste con los países de la Unión Europea en P.J. Beneyto (2008) "El sindicalismo español en perspectiva europea: de la anomalía a la convergencia", Cuadernos de Relaciones Laborales, 26, núm. 1, p. 60 y ss.

17 M. Alonso Olea (2002) Introducción al Derecho del Trabajo, $6^{\mathrm{a}}$ ed. rev., ren. y ampl.. Madrid: Civitas, p. 503 [citando a M. Biagi (1993) El Derecho del Trabajo en pequeñas y medianas empresas. Bruselas, p. 98] o A. Kaiero Uría (2000) "Los retos del sindicalismo en el siglo XXI", Lan Harremanak (Revista de Relaciones Laborales), 2, p. 97 y ss.

18 Al respecto, M.E. Casas Baamonde (1990) "Democracia, representatividad y afiliación sindicales", Cuestiones actuales de Derecho del Trabajo. Estudios ofrecidos por los catedráticos españoles de Derecho del Trabajo al Prof. Manuel Alonso Olea. Madrid: MTSS, p. 594; S. de Soto Rioja (2001) "El Derecho del Trabajo: entre la unidad y la fragmentación", Temas Laborales, 60, p. 56; S. Rodríguez Escanciano (2002) "Nuevos marcos para la acción colectiva: la implantación de 
del estudio pretendido, cabe destacar la poca tradición de libertad y las reticencias a la adscripción a cualquier ente fundadas en el anterior encuadramiento forzoso del régimen franquista ${ }^{19}$, realidad que puede ser perfectamente resumida en las siguientes palabras:

parece posible que los sindicatos, y en cierto sentido también las asociaciones empresariales, sean muy poderosos y, sin embargo, apenas tengan afiliados... En el fenómeno subyace un cambio general en las aptitudes de los trabajadores y de otros grupos sociales hacia toda forma de asociación intermediaria. En lugar de identificarse estrecha y exclusivamente con una única organización en la cual participen, se consideran miembros vicarios de muchos grupos de intereses (frecuentemente sin adherirse formalmente a ellos), amenazando con socavar el papel característico de las asociaciones en los procesos de negociación ${ }^{20}$.

No cabe olvidar tampoco el aire antisindical de las pequeñas empresas y cómo la legislación en materia de elección de los representantes del personal margina a los trabajadores precarios, al exigir tiempos mínimos de permanencia en la empresa antes de ser electores o elegibles, demandando estabilidad cuando la regla es justo la contraria ${ }^{21}$.

El resultado no puede ser más nefasto: importantes colectivos padecen cierta "alergia" sindical, y en ellos se subraya de forma rotunda una notable falta de compromiso y un paralelo alejamiento de los

un sistema de relaciones laborales más dinámico y participativo", ed. cit., p. 42 y 43 y H.J. Simón (2003) "¿Qué determina la afiliación a los sindicatos en España?", Revista del Ministerio de Trabajo y Asuntos Sociales, 41, p. 63 y ss.

19 S. Rodríguez Escanciano (2002) "Nuevos marcos para la acción colectiva: la implantación de un sistema de relaciones laborales más dinámico y participativo", ed. cit., p. 43.

En efecto, "no hay que olvidar que el factor básico de la afiliación es la percepción de los trabajadores de que una organización defiende bien sus intereses concretos y sus derechos en un marco laboral determinado... [y la] debilidad relativa de la estructura de rama [vinculada a la época de la transición] sigue siendo un elemento diferencial del sindicalismo español, y ha influido en la baja afiliación en las décadas de los 70 y 80" [J. Doz (2004) "Panorámica del sindicalismo europeo", Gaceta Sindical, 4, p. 335]. Así, "esta característica, proveniente de la proyección del sindicalismo 'desde arriba', unida al pluralismo sindical y a la fuerte relación sindicatos-partidos en los primeros momentos de la transición, pero que continuó al menos hasta 1986, fundamentó la impresión de politización de los sindicatos que las encuestas detectaron entre los trabajadores" [A. Kaiero Uría (2000) "Los retos del sindicalismo en el siglo XXI", ed. cit., p. 102].

20 P.C. Schmitter (1991) "La concertación social en perspectiva comparada", A. Espina (coord.) Concentración social, neocorporatismo y democracia. Madrid: MTSS, pp. 74-76 y J.J. Fernández Domínguez, M.R. Martínez Barroso y S. Rodríguez Escanciano (1998) El Derecho del Trabajo tras las últimas reformas "flexibilizadoras" de la relación laboral, ed. cit., p. 171.

21 B. Quintanilla Navarro (1999) Dimensión de la empresa y órganos de representación. Valencia: Tirant lo Blanch, p. 105 y ss. 
instrumentos de defensa de los intereses colectivos ${ }^{22}$, circunstancia que, a la postre, podría suponer un impedimento para la efectiva representatividad de los sindicatos ${ }^{23}$. En efecto,

las dificultades de los sindicatos son particularmente serias, puesto que la intensificación de la competencia internacional y la resultante emergencia de nuevos determinantes de la política macroeconómica, acompañados por la alta tasa de desempleo, han causado la disminución del índice de sindicación y han socavado el poder de negociación de los sindicatos ${ }^{24}$,

habida cuenta de que:

desde hace veinte años el sindicato padece un progresivo desarraigo de los sectores donde tradicionalmente se localizaba, como la industria, y se ha convertido para el universo juvenil-femenino escolarizado en quien, por otra parte, ha sido siempre para los empleados -en los últimos tiempos en gran aumento- de las pequeñas empresas: un objeto misterioso ${ }^{25}$.

\section{EL MARCO ESPAÑOL DE LA REPRESENTATIVIDAD SINDICAL: ¿UN MODELO EN CRISIS? \\ El sistema español de relaciones colectivas gravita sobre el concepto de la "mayor representatividad" constituyendo una de las piezas}

22 J.R. Mercader Uguina (2002) Derecho del Trabajo. Nuevas tecnologías y sociedad de la información. Valladolid: Lex Nova, p. 216. En este sentido, para algún autor "la explicación de todo el fenómeno de desafiliación sindical se encuentra en algo más intrínseco al concepto de sindicato: es la percepción del mismo como un organizador de huelgas y confrontaciones, como un ente conflictivo que no arregla, sino empeora los problemas, lo que se halla detrás de su debilidad"; A. Ojeda Avilés (2006) "Sindicalismo y globalización económica: el debate sobre costes de transacción y defensa de la competencia", J. García Murcia (coord.) La globalización económica y el Derecho del Trabajo. Oviedo: Consejería de Industria y Empleo/ Universidad de Oviedo, p. 70.

23 F. Valdés Dal-Ré (1996) "El sistema español de relaciones laborales: una aproximación", Relaciones Laborales, 1-2, p. 26 ó M. Iglesias Cabero (1996) Derecho Sindical y representación de los trabajadores. Madrid: Colex, p. 281.

1, p. 75.

24 M. Ozaki (1999) "Relaciones laborales y globalización", Relaciones Laborales,

25 U. Romagnoli (2001) "Redefinir las relaciones entre trabajo y ciudadanía: el pensamiento de Massimo D'Antona", J. López López (coord.) Nuevos escenarios para el Derecho del Trabajo: familia, inmigración y noción de trabajador. Homenaje a Massimo D'Antona. Madrid: Marcial Pons, p. 319 y 320. 
fundamentales dentro del Derecho Colectivo del Trabajo y, por ende, de las relaciones laborales en España. A través de esta técnica el legislador selecciona a aquellos sindicatos capaces de dar voz al conjunto de empleados, no sólo a los adheridos a él ${ }^{26}$.

El Derecho Sindical español reconoce dos grados de mayor representatividad (estatal y a nivel de Comunidad Autónoma -este último origen de un sin fin de discordancias por los parámetros elegidos ${ }^{27}-$ ), la suficiente y, aun sin mención en la clasificación, la ostentada por cuantas organizaciones carecen de semejante naturaleza. De facto, se pone en cuestión el pluralismo en una "democracia obrera" asentada sobre dos sindicatos más representativos a nivel nacional y otros tres más a nivel autonómico ${ }^{28}$.

Este instituto origina dos tipos de problemas para el movimiento sindical: por un lado, el criterio elegido parece distorsionar el mecanismo de representación unitaria de los trabajadores en las empresas; por otro, las consecuencias de institucionalización que las facultades otorgadas a los más representativos provocan, dejando un escaso margen de actuación a las organizaciones más pequeñas y llegando, en muchas ocasiones, a obstaculizar de manera significativa la pluralidad sindical, al implicar la marginación de estas últimas cuando no forzar su desaparición.

Así, en primer término, la adopción de un criterio externo al propio sindicato para medir su representatividad, como ocurre con las elecciones a delegados de personal y miembros del comité de empresa, ha supuesto, a la postre, que el doble sistema de representación (unitario y sindical), aun cuando debiera ser contemplado en términos de

26 H. Álvarez Cuesta (2006) Puntos críticos y alternativas a las elecciones sindicales y a la mayor representatividad. Granada: Comares, p. 1.

27 Al respecto, F. Rodríguez-Sañudo Gutiérrez (1986) "La representatividad sindical", M. Rodríguez-Piñero y Bravo-Ferrer (coord.) Comentarios a la Ley de Libertad Sindical. Madrid: Tecnos, p. 202; F. Navarro Nieto (1987) "El sindicato más representativo en la reciente historia normativa española", Relaciones Laborales, T. II, p. 32; M.E. Casas Baamonde (1985) "Sindicatos y Comunidades Autónomas", Revista de la Facultad de Derecho de la Universidad Complutense de Madrid, 7, p. 235 y 236 y J. García Murcia (1987) Organizaciones sindicales y empresariales más representativas. Posición jurídica y dimensión política. Madrid: MTSS, p. 92.

28 J.A. Sagardoy Bengoechea y F. Durán López (1984) El Proyecto de Ley Orgánica de Libertad Sindical. Madrid: Instituto de Estudios Económicos, p. 27; S. Rodríguez Escanciano (2002) "Nuevos marcos para la acción colectiva: la implantación de un sistema de relaciones laborales más dinámico y participativo", ed. cit., p. 41 y J. Rivero Lamas (1998) "Los sindicatos y las asociaciones empresariales veinte años después de la Constitución", Revista del Ministerio de Trabajo y Asuntos Sociales, 13, p. 594. 
complementariedad y soporte recíproco ${ }^{29}$, haya resultado un medio para llegar a un fin, generando no pocos problemas y disfunciones ${ }^{30}$, hasta el punto de hacer "dramáticamente necesario"31 sindicalizar el proceso electoral $^{32}$. De esta manera, no puede extrañar que aquellas voces más críticas hayan llegado a afirmar cómo "el engranaje o mecánica electoral es la parte enferma del cuerpo de nuestro sistema de representatividad sindical, manifiestamente precisada de correcciones y reformas normativas para sobrevivir" ${ }^{\prime 3}$.

No sin razón tras la LOLS se ha sostenido cómo "la representación unitaria adquiere su verdadera dimensión, que no es otra que la de su propia sindicalización" ${ }^{34}$ :

no importaría tanto que refleje la voluntad real de un colectivo de trabajadores de designar a uno de sus compañeros como instrumento para la gestión de sus intereses..., como que, en los resultados globales, tal o cual representante exista y sea asignado a una determinada opción sindical. Se corre así el riesgo de desvirtuar en muchos casos la elección, sustituyéndola por un mecanismo subrepticiamente plebiscitario, por lo demás complejo y tortuoso, en el cual lo relevante sea obtener el respaldo, con sólo eficacia hacia el exterior, a unas determinadas siglas, y no el garantizar la

29 A. Supiot (1999) "Transformation du travail et devenir du Droit du Travail en Europe", Droit Social, 5, p. 435. Tal ocurre con la profunda imbricación entre los organismos selectivos de representación del personal y los sindicatos, aun cuando se aluda a "compromiso", a "feliz conciliación" entre el sistema electivo al margen de las asociaciones obreras y a la designación directa de representantes por éstas, M. Rodríguez-Piñero y Bravo-Ferrer (1986) "La doble cara de las elecciones 'sindicales'", Relaciones Laborales, 10, p. 31.

30 M.F. Fernández López (1990) "De nuevo sobre la mayor representatividad: asociaciones patronales, procedimiento de elección de los representantes legales de los trabajadores; negociación colectiva. Comentario a la STCo 57/1989, de 16 de marzo", en M. Alonso Olea: Jurisprudencia Constitucional sobre Trabajo y Seguridad Social. Madrid: Civitas, T. VIII, p. 149.

31 M. Rodríguez-Piñero y Bravo-Ferrer (1981) "Las relaciones laborales en la España de los ochenta: la participación de los trabajadores en la empresa", Participación de los trabajadores en las decisiones de la empresa. Madrid: OIT, p. 59 y ss.

32 P. Gete Castrillo (1994) "La reforma del derecho de representación colectiva", F. Valdés Dal-Ré (Dtor.) La reforma del mercado de trabajo. Valladolid: Lex Nova, p. 507.

33 M.E. Casas Baamonde (1990) "Participación de los sindicatos en los órganos de control y seguimiento de las elecciones sindicales y la mayor representatividad sindical (I). Sobre la 'función típica' de la participación institucional y la eficacia anulatoria general de las sentencias de amparo (Cuando la anulada es una norma reglamentaria autonómica que ejecuta la legislación laboral del Estado)", en M. Alonso Olea: Jurisprudencia Constitucional sobre Trabajo y Seguridad Social. Madrid: Civitas, T. VIII, p. 477.

34 M. Álvarez de la Rosa (1991) La organización del sindicato en los lugares de trabajo (Empresa y Administración Pública). Madrid: Civitas, p. 32 y J. Luján Alcaraz (2003) La acción sindical en la empresa: marco legal y desarrollo convencional. Madrid: CES, p. 96. 
existencia, en esa empresa, de un cauce auténtico de representación de los intereses de la plantilla, en cuanto puerta abierta, además, a la implantación sindical en la misma ${ }^{35}$.

El resultado a seguir viene dado, por un lado, en la devaluación de los delegados y miembros del comité de empresa en su función primera y propia de representación de los intereses de los trabajadores de su ámbito, en un proceso progresivo en el cual los órganos unitarios se encuentran incursos y que acabará probablemente por convertirlos en meros instrumentos al servicio del cómputo y organización de la mayor representatividad ${ }^{36}$. Por otro, la utilización de los comicios ha contribuido a apuntalar la institucionalización del modelo, convirtiendo en aún más indiferenciables las ya difíciles fronteras entre la actividad de defensa obrera y el propio de la política ${ }^{37}$.

Al final, el recurso a la audiencia obtenida en las elecciones a representantes unitarios como criterio único e incontrovertible va a propiciar la escasa afiliación por parte de los trabajadores ${ }^{38}$, en tanto los sindicatos pueden caer en la tentación de luchar, no por los intereses de los obreros, sino para lograr una mayor representatividad ${ }^{39}$.

En segundo lugar, las amplias facultades concedidas a los sindicatos más representativos (compartidas o incluso algunas en régimen Laborales, 10-11, p. 11

35 S. González Ortega (1987) "Balance de las elecciones sindicales", Temas

$36 \quad$ F.J. Prados de Reyes (1991) "Representación unitaria y representación sindical en la empresa. Evolución de sistemas", Relaciones Laborales, 7, p. 26. sindicales", ed. cit., p. 607.

37 M.E. Casas Baamonde (1990) "Democracia, representatividad y afiliación

38 R. Escudero Rodríguez (1990) La representatividad de los sindicatos en el modelo laboral español. Madrid: Tecnos, p. 94; T. Treu (1988) "Innovazione e regole della rappresentanza sindacale", Lavoro e Diritto, 2, p. 225; M. Rodríguez-Piñero y Bravo-Ferrer (1986) "La doble cara de las elecciones 'sindicales"', ed. cit., p. 34; A. Baylos Grau (1991) Derecho del Trabajo: un modelo para armar. Madrid: Trotta, p. 133; M.E. Casas Baamonde (1990) "Jurisprudencia constitucional y representatividad sindical", Temas Laborales, 19-20, p. 47; A.J. Gallego Morales (1997) Los intereses profesionales y las fórmulas organizativas, Granada, Universidad de Granada, p. 314; F. Suárez González (1990) "La situación sindical en España", Los sindicatos en la sociedad industrial desarrollada. Madrid: Universidad Complutense de Madrid, p. 53 ó F. Valdés Dal-Ré (1988) "Representación y representatividad sindicales en España", Relaciones Laborales, T. II, p. 65 y (1996) "El sistema español de relaciones laborales: una aproximación", ed. cit., p. 26.

39 "La escasa afiliación de los sindicatos que gozan de una gran audiencia puede hacer caer al dirigente sindical en la tentación de que no se debe a sus afiliados, sino a sus votantes", M. Rodríguez-Piñero y Bravo-Ferrer (1985) "La estructura y el funcionamiento democrático de los sindicatos", Revista de la Facultad de Derecho de la Universidad Complutense de Madrid, 7, p. 170. 
de monopolio) -tales como participación institucional, concertación social, negociación colectiva, sistemas no jurisdiccionales de solución de conflictos, acción sindical en la empresa, subvenciones públicas y cesión de bienes inmuebles ${ }^{40}-$, han acarreado un proceso de institucionalización -burocratización como lo han llamado algunos ${ }^{41}$ - de las organizaciones obreras, hasta el punto de que este "acercamiento a los poderes públicos puede significar una progresiva pérdida de contacto entre la organización y el afiliado", abriendo una brecha difícil de soldar en su función representativa ${ }^{42}$. Los sindicatos dejan a un lado su actitud de mera reivindicación para adoptar otra de mayor moderación ${ }^{43}$, haciéndose partícipes de la gestión de la economía y del empleo ${ }^{44}$, al punto de poder aludir a una verdadera "crisis de identidad" 45 .

El modelo de relaciones laborales en España acaba siendo, así, desequilibrado en su esencia, pues el escenario dominante de la acción obrera ha sido el político, a cuyo servicio se han establecido los objetivos y elaborado los métodos. El sindicato ha tendido a comportarse preferentemente como contrapoder político y no económico; sin poder afirmar, por otra parte, que, pese a sus meritorios esfuerzos, haya logrado actuar como sujeto político y no como simple objeto de la política ${ }^{46}$.

40 Un estudio actual de las mismas en $\mathrm{H}$. Álvarez Cuesta (2006) Puntos críticos y alternativas a las elecciones sindicales y a la mayor representatividad, ed. cit., p. 123 y ss.

41 R. Escudero Rodríguez (1994) "Logros y retos de la mayor representatividad en la década de los noventa", F. Valdés Dal-Ré (coord.) Sindicalismo y cambios sociales. Madrid: CES, p. 101. "Politización del sindicato", según palabras de P. Gete Castrillo (1994) "La reforma del derecho de representación colectiva", ed. cit., p. 514.

42 J. García Murcia (1987) Organizaciones sindicales y empresariales más representativas. Posición jurídica y dimensión política, ed. cit., p. 214; A. Ojeda Avilés (1992) "La representatividad sindical como excepción", Relaciones Laborales, T. I, p. 13; D. Lantarón Barquín (2000) "Reflexiones en torno al devenir del sindicato y a los factores que influyen en su evolución: ¿crisis y/o metamorfosis?", ed. cit., p. 70 y J.R. Mercader Uguina (2003) "Sistema de fuentes y globalización", ed. cit., p. 681. Economía Española, 22, p. 230

43 F. Durán López (1985) "Sindicatos y salida concertada a la crisis", Papeles de

44 M.C. Ortiz Lallana (1986) "Líneas de tendencia y problemas fundamentales del sector jurídico-laboral en las sociedades industriales: el caso español", Revista de Trabajo, 82, p. 113.

45 M. Rodríguez-Piñero y Bravo-Ferrer (1991) "El sindicalismo de los años 90", VIII Jornadas Universitarias Andaluzas de Derecho del Trabajo y Relaciones Laborales. Sevilla: Consejo Andaluz de Relaciones Laborales, p. 25 y ss. Esta institucionalización del sindicato llevó a pergeñar una nueva tipología de organizaciones, las que basan su fuerza en la afiliación (sindicato asociación) y cuantas la fundamentan en los privilegios de la ley (sindicato institución); al respecto, A. Kaiero Uría (2000) "Los retos del sindicalismo en el siglo XXI", ed. cit., p. 102.

46 F. Valdés Dal-Ré (1996) "El sistema español de relaciones laborales: una aproximación", ed. cit., p. 52. 
Ante tal perspectiva resulta perentorio abogar y reivindicar el espacio propio para un nuevo rol del sindicalismo en el siglo XXI: búsqueda de un sistema de relaciones laborales más libre y participativo ${ }^{47}$, en tanto en cuanto decrece la intervención de los órganos públicos y aumenta el protagonismo de los sujetos de la relación de trabajo y éstos parecen recuperar algunas parcelas o conquistar otras nuevas para el consenso y la negociación ${ }^{48}$, siendo necesario "consolidar con métodos democráticos la legitimación político-social de los sujetos que necesariamente han de gestionar la transición del trabajo declinado en singular al trabajo declinado en plural"49.

En consecuencia, deben redefinir su papel dentro de la comunidad, incluso su participación en cuanto agentes políticos, pues

no debe perderse de vista que sólo conseguirán ser sujetos políticos de auténtico peso específico dentro de la sociedad, capaces por tanto de permanecer inmunes a todo intento de instrumentalización desde el poder, únicamente en la medida en que logren configurarse, paralelamente, como sujetos contractuales fuertes. Es decir, en tanto cuenten con el respaldo y la adhesión de los trabajadores, por ser capaces de gestionar adecuadamente sus intereses en los distintos ámbitos en los que éstos se expresan, y no sólo en el terreno del intercambio político ${ }^{50}$.

La lucha contra la institucionalización, y la pérdida de afiliados aneja, pasa por "la participación efectiva del afiliado en la toma de decisiones, y la existencia de mecanismos adecuados de control y vigilancia pueden ayudar, sin duda, a que la organización siga más de cerca los intereses de los representados"51.

47 F. Durán López (1996) "El futuro del Derecho del Trabajo", Revista Española de Derecho del Trabajo, 78, p. 609.

48 M.C. Ortiz Lallana (1999) La transformación del Derecho del Trabajo ante los nuevos retos sociales. Logroño: Universidad de La Rioja, p. 42.

49 U. Romagnoli (2001) "Redefinir las relaciones entre trabajo y ciudadanía: el pensamiento de Massimo D'Antona", ed. cit., p. 322.

50 W. Sanguineti Raymond (1999) "Libertad sindical y rol institucional de los sindicatos: anotaciones a dos décadas de vigencia del texto constitucional", Revista de Derecho Social, 8, p. 55 y 56 y S. Rodríguez Escanciano (2002) "Nuevos marcos para la acción colectiva: la implantación de un sistema de relaciones laborales más dinámico y participativo", ed. cit., p. 23.

51 J. García Murcia (1987) Organizaciones sindicales y empresariales más representativas. Posición jurídica y dimensión política, ed. cit., p. 214. Amén de servir al cumplimiento del principio de democracia sindical interna, J.P. Landa Zapirain (1996) Democracia sindical interna (Régimen jurídico de la organización y funcionamiento de los sindicatos). Madrid: Civitas, especialmente p. 151 y ss. 
Ahora bien, la tarea, menester es reconocerlo, resulta ardua y llena de obstáculos, habida cuenta no existen soluciones fáciles capaces de combinar de manera equilibrada el grado más amplio de pluralismo sindical con el necesario reconocimiento de ciertos privilegios para quienes representan los intereses de la mayoría pues resultaría poco equitativa establecer idéntica posición jurídica para todos; en consecuencia, se hacen necesarias fórmulas imaginativas capaces de expresar de manera lo más fiel posible la implantación sindical. En este sentido, y sin pretender imponer ninguna solución como la ideal, no parece descabellado abogar por una mezcla entre los criterios de representatividad electoral y afiliación tal y como se ha propuesto en Italia, a través del promedio de dos variables, a saber: "el porcentaje de las afiliaciones en el sector respecto del número total de afiliaciones y el porcentaje de votos respecto del total de votos emitidos para la elección de los órganos de representación unitaria del personal"52.

4. LA EXTENSIÓN DE SU MARCO DE ACTUACIÓN HACIA LOS NUEVOS GRUPOS DE TRABAJADORES

Los anteriores retos que se plantean de un modo acuciante al sindicato acaban por desembocar en éste:

averiguar cómo restituir al sindicato, que había sabido transportar, en el arco de un siglo aproximadamente, la pobreza laboriosa de masas de artesanos ya no del todo artesanos, y campesinos ya no del todo campesinos, de la marginación a la ciudadanía industrial..., la confianza en sí mismo, la fuerza y el coraje de la innovación que es precisa para edificar la ciudadanía industriosa del Dos $\mathrm{Mil}^{53}$.

Por un lado,

las exigencias de tutela de la situación de los trabajadores cada vez exceden más de las relativamente sencillas cuestiones tradicionales relativas a la remuneración y a las condiciones de trabajo. En ellas están implicadas, de

52 U. Romagnoli (2001) "Redefinir las relaciones entre trabajo y ciudadanía: el pensamiento de Massimo D'Antona", ed. cit., p. 321.

53 Ibid., p. 320. 
manera creciente, decisiones estratégicas de las empresas, estrechamente dependientes del marco económico en que han de operar, y los cambios inducidos en la situación profesional de los trabajadores ${ }^{54}$

$y$, en consecuencia, los sindicatos han pasado a diseñar una política global respecto a las condiciones laborales dentro de la unidad productiva y a participar e influir en la estrategia empresarial, viniendo a defender los intereses de los empleados en su totalidad y sin ceñir su ámbito reivindicativo a la relación de intercambio entre prestación de servicios y retribución.

Por otra parte, está comenzando a desaparecer el trabajo subordinado estable en una empresa organizada de forma centralizada y jerárquica en la cual todos prestan servicios a un mismo tiempo, en un mismo lugar y a las órdenes directas de la dirección. Baste mencionar la temida "flexibilización" del trabajo, con el aumento consiguiente del temporal, de sindicación difícil, y la opción por unidades de nueva creación en favor de la ocupación de personas no afiliadas ${ }^{55}$ o la introducción de nuevas tecnologías, las cuales han contribuido a fragmentar aún más a los trabajadores $^{56}$.

\section{En consecuencia,}

el problema capital que han planteado a los sindicatos de los países industrializados las nuevas bases es la dificultad de agregar sus reivindicaciones en torno a la figura profesional hegemónica, esto es, en torno al trabajador-masa de la fábrica fordista, que gozaba de una estabilidad en el empleo y estaba habituado a que aquéllos le consiguieran progresivos aumentos de retribuciones sin asumir riesgos empresariales, al tiempo que afirmaban su poder sobre la organización del trabajo

54 F. Durán López (1998) "Globalización y relaciones de trabajo", Revista Española de Derecho del Trabajo, 92, p. 885.

55 M. Alonso Olea (2002) Introducción al Derecho del Trabajo, 6 a ed., ed. cit., p. 502.

56 Al respecto, M. Nogueira Guastavino (2001) Sindicato y negociación colectiva franja. Valencia: Tirant lo Blanch, p. 50 y ss., analizando esta fragmentación y el consecuente nacimiento de otros sindicatos y de sus estrategias de negociación y acción colectiva. 


\section{en la unidad productiva frente a las prerrogativas del empleador $^{5}$}

en otras palabras, el problema radica en "cómo tratar sindicalmente las múltiples manifestaciones de la 'huida' del trabajo asalariado hacia la tierra de nadie de la inexistencia de derechos colectivos y de la norma legal que garantiza estándares mínimos de vida"58, pues la indicada segmentación "hace decididamente de éste una realidad menos compacta y uniforme de lo que lo era en el pasado, dificultando consiguientemente la tarea de representación de intereses" ${ }^{\prime 59}$. En semejante contexto, debe resolver los retos planteados a la "situación real actual"60, "comenzando a preocuparse por los grupos laborales más vulnerables y por la situación de los excluidos"61.

Así, habrá de acercarse y dar respuesta a los problemas específicos de colectivos como los trabajadores con contratos precarios, los inmigrantes, las mujeres, los discapacitados o los desocupados de larga duración, cuyas inquietudes distan de manera sustancial de las preocupaciones del tradicional trabajador del modelo fordista, realizando una completa labor de síntesis capaz de mezclar y articular los intereses

57 J. Rivero Lamas (1997) "El empleo y las relaciones laborales en el umbral del siglo XXI", Temas Laborales, 44, p. 19 y A. Supiot (coord.) (1999) Trabajo y empleo. Transformaciones del trabajo y futuro del Derecho del Trabajo en Europa. Valencia: Tirant lo Blanch, p. 171 y 172. Un análisis de la fábrica neofordista y la representación en ella en esta época en A. Baylos Grau y J.L. López Bulla (2003) "Sobre el actual modelo de representación", Revista de Derecho Social, 22, p. 227 y ss. o J.L. Monereo Pérez (2000) "El Derecho Social en el umbral del siglo XXI: la nueva fase del Derecho del Trabajo", Lan Harremanak (Revista de Relaciones Laborales), 2, p. 253 y ss.

"La pervivencia de prácticas inerciales, esto es, el mantenimiento de arquetipos sindicales ya superados está, sin lugar a dudas, condenado al fracaso. Como son, por ejemplo, el anclaje en pautas ceñidas al prototipo del trabajador varón, de edad intermedia, que presta sus servicios en una empresa de tamaño medio o grande del sector industrial, situada en una zona de una importante actividad económica", R. Escudero Rodríguez (1994) "Logros y retos de la mayor representatividad en la década de los noventa", ed. cit., p. 98. proyecto", ed. cit., p. 41

58 A. Baylos Grau (1999) "Globalización y Derecho del Trabajo: Realidad y

59 F. Pérez de los Cobos Orihuel (2007) "El sindicato ante las transformaciones económicas y sociales", Revista Española de Derecho del Trabajo, 134, p. 295.

60 J.R. Mercader Uguina (2002) Derecho del Trabajo. Nuevas tecnologías y sociedad de la información, ed. cit., p. 216 y S. Rodríguez Escanciano (2002) "Nuevos marcos para la acción colectiva: la implantación de un sistema de relaciones laborales más dinámico y participativo", ed. cit., p. 58.

61 J.L. Monereo Pérez (2000) "El Derecho Social en el umbral del siglo XXI: la nueva fase del Derecho del Trabajo", ed. cit., p. 293 y (1992) Los derechos de información de los representantes de los trabajadores, ed. cit., p. 150 y 151. Sobre la acción sindical referida a los sujetos fuera del círculo de trabajo asalariado y sus posibles problemas, A. Baylos Grau (2001) "Representación y representatividad sindical en la globalización", ed. cit., p. 75 y ss. 
de unos y de otros de manera equilibrada ${ }^{62}$; de esta manera, "la obsoleta idea del trabajador masa o uniforme debe ser sustituida por el trabajador que tiene edad, sexo, posición y relaciones sociales, origen étnico y trayectoria ocupacional y vital"63, se trataría, como gráfica y acertadamente se ha señalado, de "gobernar la diversidad"64.

Ante tales circunstancias, el modelo sindical, y no la propia organización, entra en crisis, debiendo repensarse a sí mismo para ser todavía protagonista ${ }^{65}$, pues las empresas a través de la subcontratación o de la filiación pueden sustraerse al marco sectorial y diversificar de alguna manera sus interlocutores y sus convenios colectivos, privilegiando las soluciones socialmente menos constrictivas. A la inversa, los sindicatos siguen apegados al marco sectorial y no pueden, por tanto, amoldarse a las nuevas formas de organización del capital. El sector profesional es, de este modo, una "jaula de hierro en la que se halla encerrada la representación de los trabajadores, pero cuya puerta está abierta para los empresarios" 66 .

Incluso aunque las organizaciones obreras mantuvieran su capacidad de representación en las empresas, controlando a tal efecto la flexibilización de los mercados internos, les resultaría igualmente difícil representar a los excluidos ${ }^{67}$. La propia cohesión social, fundamento de la acción colectiva, tiende a erosionarse ${ }^{68}$ :

el debate en el que se halla inmerso actualmente el sindicato no es sólo el de la representatividad, sino también el de su eficacia y legitimación. Se plantea en este momento su capacidad de justificar la propia

\footnotetext{
62 M. D'Antona (1998) "Diritto del lavoro di fine secolo: una crisi d'idendità?", Rivista Giuridica del Lavoro e della Previdenza Sociale, T. I, p. 317.

63 R. Alós Moner (2008) "Segmentación de los mercados de trabajo y relaciones laborales. El sindicalismo ante la acción colectiva", Cuadernos de Relaciones Laborales, 26, núm. 1, p. 138.

64 J. Cruz Villalón (2007) "La actividad sindical en la empresa: viejos y nuevos problemas", Relaciones Laborales, T. II, p. 727.

65 Citando a Altamira, M. Rodríguez-Piñero y Bravo-Ferrer (1995) "Diálogo social, participación y negociación colectiva", Relaciones Laborales, 23, p. 7.

66 A. Supiot (coord.) (1999) Trabajo y empleo. Transformaciones del trabajo y futuro del Derecho del Trabajo en Europa, ed. cit., p. 197.

67 J. Bunel (1994) "El sindicalismo sometido a la prueba de la flexibilidad", F. Valdés Dal-Ré (coord.) Sindicalismo y cambios sociales. Madrid: CES, p. 55.

68 F. Valdés Dal-Ré (2003) "Transformaciones del Derecho del Trabajo y orden económico globalizado", Revista de la Asociación Estatal de Centros Universitarios de Relaciones Laborales y Ciencias del Trabajo, 12, p. 147.
} 
existencia, esto es, la necesidad de una institución que, trascendiendo los intereses individuales, se convierta en instrumento de defensa del interés colectivo, en el cual actualizar la idea de que a su través se conseguirá algo más de lo que conseguiría el individuo aislado; pero también está en juego su legitimidad social, esto es, la adecuación entre lo que manifiesta y las funciones y papel que realmente juega en nuestra sociedad ${ }^{69}$.

Con miras a combatir estos negros augurios, conviene pertrechar a las organizaciones obreras no sólo de los medios de acción necesarios, sino también de la sensibilización precisa ${ }^{70}$, comenzando este largo camino por su núcleo de acción primario, la empresa, pues su futuro depende de la capacidad de proporcionar respuestas satisfactorias a las demandas de un mundo laboral caracterizado por su heterogeneidad y movilidad, lo cual exige de manera inevitable articular y adaptar sus opciones estratégicas y medios tácticos a las transformaciones de fondo ${ }^{71}$ :

en ese proceso se juegan estas organizaciones su futuro como instituciones y su propio peso político y social. No debe perderse de vista que, de no responder a los retos planteados por esta nueva fase en el desarrollo de las relaciones industriales, pasarán seguramente a convertirse en organizaciones burocráticas, representativas de un núcleo cada vez más reducido de trabajadores ${ }^{72}$.

En consecuencia, y en virtud de las variables apuntadas, cabe asistir a una globalización o expansión creciente de los objetivos sindicales que, sin abandonar sus fines clásicos, hagan referencia, no tanto a intereses de los trabajadores como tales, cuanto a intereses de los ciudadanos en general ${ }^{73}$ : reforma fiscal, política de medio ambiente,

69 J.R. Mercader Uguina (2002) Derecho del Trabajo. Nuevas tecnologías y sociedad de la información, ed. cit., p. 213. Es necesario un sindicalismo fuerte, capaz, bien liderado, con cabezas pensantes y medios suficientes, esto es, un sindicalismo "redivivo", J.A. Sagardoy Bengoechea (2004) Las relaciones laborales en España, 1973-2003. Madrid: Cinca, pp. 97-98.

70 M. Rodríguez-Piñero y Bravo-Ferrer (1985) "La Ley Orgánica de Libertad Sindical", Relaciones Laborales, 9, p. 4.

71 S. Rodríguez Escanciano (2002) "Nuevos marcos para la acción colectiva: la implantación de un sistema de relaciones laborales más dinámico y participativo", ed. cit., p. 59. Un análisis de las distintas vías de actuación a este nivel en A. Martín Artiles (1995) Flexibilidad y relaciones laborales. Estrategias empresariales y acción sindical. Madrid: CES.

72 W. Sanguineti Raymond (1999) "Libertad sindical y rol institucional de los sindicatos: anotaciones a dos décadas de vigencia del texto constitucional", ed. cit., p. 59.

73 F. Valdés Dal-Ré (1996) "El sistema español de relaciones laborales: una aproximación", ed. cit., pp. 51-52. No cabe excluir a priori que, andando el camino, el sindicato se 
de vivienda o legislativa ${ }^{74} .$. ; mostrando la clara intención y aspiración de constituir, más que únicamente organizaciones representativas de los intereses de los trabajadores, "vehículos universales de progreso social, económico y político" ${ }^{15}$.

Para ello las vías más inmediatas de contacto consisten en dos complementarias: por un lado, la acción sindical a nivel de centro de trabajo y empresa ("se ha pasado a una situación de revalorización de la actividad de representación en la empresa, en el conjunto del funcionamiento de un determinado sistema de relaciones laborales ${ }^{176}$ ); por otro, la acción en la sociedad y, como núcleo próximo y parte primordial, dentro de la empresa ${ }^{77}$.

\section{BIBLIOGRAFÍA}

Alonso Olea, M. (1990) Cuestiones actuales de Derecho del Trabajo. Estudios ofrecidos por los catedráticos españoles de Derecho del Trabajo al Prof. Manuel Alonso Olea. Madrid: Centro de Publicaciones, Ministerio de Trabajo y Seguridad Social.

convenza de que su función ha quedado convertida en "representar al trabajador en cuanto ciudadano más que al ciudadano en cuanto trabajador", U. Romagnoli (2001) "Redefinir las relaciones entre trabajo y ciudadanía: el pensamiento de Massimo D'Antona", ed. cit., p. 323.

74 A. Montoya Melgar (1989) "Sindicatos y Constitución", Anuario de Derecho Constitucional y Parlamentario, Vol. I, p. 129.

75 A. Montoya Melgar (1991) "Presente y futuro de los sindicatos (Los sindicatos en la década de los noventa)", E. Borrajo Dacruz (dir.) El cambio laboral en la década de los 90. Madrid: Ciencias de la Dirección, p. 32 y J.J. Fernández Domínguez, M.R. Martínez Barroso y S. Rodríguez Escanciano (1998) El Derecho del Trabajo tras las últimas reformas "flexibilizadoras" de la relación laboral, ed. cit., pp. 175-176.

76 J. Cruz Villalón (1992) La representación de los trabajadores en la empresa y en el grupo. Sevilla: Trotta, p. 18. Además, esta participación fomenta la democracia industrial, J.M. Galiana Moreno y B. García Romero (2003) "La participación y representación de los trabajadores en la empresa en el modelo normativo español", Revista del Ministerio de Trabajo y Asuntos Sociales, 43 , p. 13 y ss.

77 La evolución vendría dada por un sindicalismo centrado en los trabajadores de la empresa, pero sin renunciar a asumir la diversificación de las formas de empleo e integrar en el ámbito de la representación colectiva a trabajadores que en la actualidad se encuentran más o menos excluidos de ella; sobre tal propuesta, A. Supiot (coord.) (1999) Trabajo y empleo. Transformaciones del trabajo y futuro del Derecho del Trabajo en Europa, ed. cit., p. 194. Propugnando también la intervención directa del sindicato en las pequeñas y pequeñísimas empresas, M.L. Rodríguez Fernández (2004) "Participación sindical", R. Escudero Rodríguez (coord.) La negociación colectiva en España: una visión cualitativa. Valencia: Tirant lo Blanch, p. 857. 
- (1955, 2000) Pactos colectivos y contratos de grupo. Madrid: Gráficas González y Granada, Comares.

- (2002) Introducción al Derecho del Trabajo, $6^{\mathrm{a}}$ ed. rev., ren. y ampl.. Madrid: Civitas.

Alós MONER, R. (2008) "Segmentación de los mercados de trabajo y relaciones laborales. El sindicalismo ante la acción colectiva", Cuadernos de Relaciones Laborales, 26, núm. 1, pp. 123-148.

Álvarez CUeSTA, H. (2006) La mayor representatividad. León: Universidad de León.

- (2006) Puntos críticos y alternativas a las elecciones sindicales y a la mayor representatividad. Granada: Comares.

ÁlVAREZ DE LA ROSA, M. (1991) La organización del sindicato en los lugares de trabajo (Empresa y Administración Pública). Madrid: Civitas.

ANTENAS COLLDERRAM, J.M. (2008) "Los sindicatos ante la globalización. ¿Hacia qué nuevas formas de solidaridad internacional?", Cuadernos de Relaciones Laborales, 26, núm. 1, pp. 35-55.

BAYLOS GRAU, A. (1991) Derecho del Trabajo: un modelo para armar. Madrid: Trotta.

- (1999) "Globalización y Derecho del Trabajo: Realidad y proyecto", Cuadernos de Relaciones Laborales, 15, pp. 19-49.

- (2001) "Representación y representatividad sindical en la globalización", Cuadernos de Relaciones Laborales, 19, pp. 69-94.

- y J.L. LÓPEZ BULLA (2003) "Sobre el actual modelo de representación", Revista de Derecho Social, 22, pp. 227-240.

BENEYTO, P.J. (2008) "El sindicalismo español en perspectiva europea: de anomalía a la convergencia", Cuadernos de Relaciones Laborales, 26, núm. 1, pp. 57-88.

BORRAJO DACRUZ, E. (dir.) (1991) El cambio laboral en la década de los 90. Madrid: Ciencias de la Dirección.

BUNEL, J. (1994) "El sindicalismo sometido a la prueba de la flexibilidad". F. VALDÉS DAL-RÉ (coord.) Sindicalismo y cambios sociales. Madrid: Consejo Económico y Social, pp. 39-57.

CASAS BAAMONDE, M.E. (1985) "Sindicatos y Comunidades Autónomas", Revista de la Facultad de Derecho de la Universidad Complutense de Madrid, 7, pp. 189-240.

- (1990) "Democracia, representatividad y afiliación sindicales". M. ALONSO OLEA: Cuestiones actuales de Derecho del Trabajo. Estudios ofrecidos 
por los catedráticos españoles de Derecho del Trabajo al Prof. Manuel Alonso Olea. Madrid: Ministerio de Trabajo y Seguridad Social, pp. 589610.

- (1990) "Jurisprudencia constitucional y representatividad sindical", Temas Laborales, 19-20, pp. 41-79.

- (1990) "Participación de los sindicatos en los órganos de control y seguimiento de las elecciones sindicales y la mayor representatividad sindical (I). Sobre la 'función típica' de la participación institucional y la eficacia anulatoria general de las sentencias de amparo (Cuando la anulada es una norma reglamentaria autonómica que ejecuta la legislación laboral del Estado)". M. ALONSO OLEA: Jurisprudencia Constitucional sobre Trabajo y Seguridad Social, T. VIII. Madrid: Civitas, pp. 37-69.

- (1997) "Las transformaciones del trabajo y de las relaciones colectivas", Relaciones Laborales, 23, pp. 88-101.

- (1999) "Nuevas tendencias de la negociación colectiva en Europa". Empleo, contratación y negociación colectiva. XI Jornadas de Estudio sobre la Negociación Colectiva. Madrid: Ministerio de Trabajo y Asuntos Sociales, pp. 67-106.

ChAVES GonzÁlez, M. (1990) Los sindicatos en la sociedad industrial desarrollada. Madrid: Universidad Complutense.

CRUZ VILLALÓN, J. (1992) La representación de los trabajadores en la empresa y en el grupo. Sevilla: Trotta.

- (2007) "La actividad sindical en la empresa: viejos y nuevos problemas", Relaciones Laborales, T. II, pp. 707-731.

D'ANTONA, M. (1998) "Contrattazione collettiva e concertazione nella formazione del diritto sociale europeo". A. LetTIERI y U. ROMAGNOLI (dirs.) La contrattazione collettiva europea. Roma: Ediesse, pp. 101-114.

- (1998) "Diritto del lavoro di fine secolo: una crisi d'idendità?", Rivista Giuridica del Lavoro e della Previdenza Sociale, T. I, pp. 311-332.

Doz, J. (2004) "Panorámica del sindicalismo europeo", Gaceta Sindical, 4, pp. 327-352.

DURÁn LóPEZ, F. (1985) "Sindicatos y salida concertada a la crisis", Papeles de Economía Española, 22, pp. 316-328.

- (1996) "El futuro del Derecho del Trabajo", Revista Española de Derecho del Trabajo, 78, pp. 601-608.

- (1998) "Globalización y relaciones de trabajo", Revista Española de Derecho del Trabajo, 92, pp. 689-888. 
ESCUDERO RODRÍGUEZ, R. (1990) La representatividad de los sindicatos en el modelo laboral español. Madrid: Tecnos.

- (1994) "Logros y retos de la mayor representatividad en la década de los noventa". F. VALDÉs DAL-RÉ (coord.) Sindicalismo y cambios sociales. Madrid: Consejo Económico y Social, pp. 89-105.

- (coord.) (2004) La negociación colectiva en España: una visión cualitativa. Valencia: Tirant lo Blanch.

ESPINA, A. (coord.) (1991) Concentración social, neocorporatismo y democracia. Madrid: Ministerio de Trabajo y Seguridad Social.

FERNÁNDEZ DOMíngueZ, J.J.; M.R. MARTíneZ BARRoso y S. RODRÍGUEZ ESCANCIANO (1998) El Derecho del Trabajo tras las últimas reformas "flexibilizadoras" de la relación laboral. Madrid: Consejo General del Poder Judicial.

FERNÁNDEZ LóPEZ, M.F. (1990) "De nuevo sobre la mayor representatividad: asociaciones patronales, procedimiento de elección de los representantes legales de los trabajadores; negociación colectiva. Comentario a la STCo 57/1989, de 16 de marzo". M. ALONSO OLEA: Jurisprudencia Constitucional sobre Trabajo y Seguridad Social, T. VIII. Madrid: Civitas, pp. 127-158.

FUndaCión PAZ y SOLIDARIDAD "SERAFín AliagA" (2001) Globalización, trabajo y movimiento sindical. Madrid: Fundación Paz y Solidaridad.

Galiana Moreno, J.M. y B. García Romero (2003) "La participación y representación de los trabajadores en la empresa en el modelo normativo español", Revista del Ministerio de Trabajo y Asuntos Sociales, 43, pp. 13-30.

GALlEGo MORALES, A.J. (1997) Los intereses profesionales y las fórmulas organizativas. Granada: Universidad de Granada.

GARCíA MURCIA, J. (1987) Organizaciones sindicales y empresariales más representativas. Posición jurídica y dimensión política. Madrid: Ministerio de Trabajo y Seguridad Social.

- (coord.) (2006) La globalización económica y el Derecho del Trabajo. Oviedo: Consejería de Industria y Empleo/Universidad de Oviedo.

Gete CASTRILlo, P. (1994) "La reforma del derecho de representación colectiva". F. VALDÉS DAL-RÉ (dir.) La reforma del mercado de trabajo. Valladolid: Lex Nova, pp. 499-563.

GonZÁlEZ ORTEGA, S. (1987) "Balance de las elecciones sindicales", Temas Laborales, 10-11, pp. 7-15. 
IgLESIAS CABERO, M. (1996) Derecho Sindical y representación de los trabajadores. Madrid: Colex.

JUNTA DE ANDALUCÍA (1991) VIII Jornadas Universitarias Andaluzas de Derecho del Trabajo y Relaciones Laborales. Sevilla: Consejería de Empleo y Desarrollo Tecnológico.

KAIERo UríA, A. (2000) "Los retos del sindicalismo en el siglo XXI", Lan Harremanak (Revista de Relaciones Laborales), 2, pp. 91-108.

LANDA ZAPIRAIN, J.P. (1996) Democracia sindical interna (Régimen jurídico de la organización y funcionamiento de los sindicatos). Madrid: Civitas.

LANTARÓN BARQuín, D. (2000) "Reflexiones en torno al devenir del sindicato y a los factores que influyen en su evolución: ¿crisis y/o metamorfosis?", Revista de Derecho Social, 10, pp. 55-80.

LETTIERI, A. y U. Romagnoli (dirs.) (1998) La contrattazione collettiva europea. Roma: Ediesse.

LÓPEZ LÓPEZ, J. (coord.) (2001) Nuevos escenarios para el Derecho del Trabajo: familia, inmigración y noción de trabajador. Homenaje a Massimo D'Antona. Madrid: Marcial Pons.

LUJÁn AlCARAZ, J. (2003) La acción sindical en la empresa: marco legal y desarrollo convencional. Madrid: Consejo Económico y Social.

MARTÍN ARTILES, A. (1995) Flexibilidad y relaciones laborales. Estrategias empresariales y acción sindical. Madrid: Consejo Económico y Social.

MeRCADER Uguina, J.R. (2002) Derecho del Trabajo. Nuevas tecnologías y sociedad de la información. Valladolid: Lex Nova.

- (2003) "Sistema de fuentes y globalización", Revista Española de Derecho del Trabajo, 119, pp. 667-690.

MINISTERIO DE TRABAJO Y ASUNTOS SOCIALES (1999) Empleo, contratación y negociación colectiva. XI Jornadas de Estudio sobre la Negociación Colectiva. Madrid: Ministerio de Trabajo y Asuntos Sociales.

MONEREO PÉREZ, J.L. (1992) Los derechos de información de los representantes de los trabajadores. Madrid: Civitas.

- (2000) "El Derecho Social en el umbral del siglo XXI: la nueva fase del Derecho del Trabajo", Lan Harremanak (Revista de Relaciones Laborales), 2, pp. 237-300.

Montoya Melgar, A. (1989) "Sindicatos y Constitución", Anuario de Derecho Constitucional y Parlamentario, I, pp. 121-148. 
- (1991) "Presente y futuro de los sindicatos (Los sindicatos en la década de los noventa)". E. BORRAJO DACRUZ (dir.) El cambio laboral en la década de los 90. Madrid: Ciencias de la Dirección, pp. 30-45.

NAVARRo NieTo, F. (1987) "El sindicato más representativo en la reciente historia normativa española", Relaciones Laborales, T. II, pp. 280-314.

NogueIRA GUASTAVINo, M. (2001) Sindicato y negociación colectiva franja. Valencia: Tirant lo Blanch.

OJEDA AVILÉs, A. (1992) "La representatividad sindical como excepción", Relaciones Laborales, T. I, pp. 238-252.

- (2006) "Sindicalismo y globalización económica: el debate sobre costes de transacción y defensa de la competencia". J. GARCíA MURCIA (coord.) La globalización económica y el Derecho del Trabajo. Oviedo: Consejería de Industria y Empleo/Universidad de Oviedo, pp. 65-102.

ORgANIZACIÓN INTERNACIONAL DEL TRABAJO (1981) Participación de los trabajadores en las decisiones de la empresa. Ginebra: Oficina Internacional del Trabajo.

ORTIZ LaLLANA, M.C. (1986) "Líneas de tendencia y problemas fundamentales del sector jurídico-laboral en las sociedades industriales: el caso español", Revista de Trabajo, 82, pp. 93-124.

- (1999) La transformación del Derecho del Trabajo ante los nuevos retos sociales. Logroño: Universidad de La Rioja.

OZAKI, M. (1999) "Relaciones laborales y globalización", Relaciones Laborales, 1, pp. 72-78.

PALACIO MORENA, J.I. (1993) "Prólogo". D. AlBers et al.: La política regional de los sindicatos europeos. Un análisis comparativo. Madrid: Ministerio de Trabajo y Seguridad Social, pp. 13-25.

Palomeque LóPeZ, M.C. (1986) Derecho Sindical español. Madrid: Tecnos.

PÉREZ DE LOS COBOS ORIHUEL, F. (2007) "El sindicato ante las transformaciones económicas y sociales", Revista Española de Derecho del Trabajo, 134, pp. 289-306.

PitXer I CAMPOS, J.V. y A. SÁNChez Velasco (2008) "Estrategias sindicales y modelo económico español", Cuadernos de Relaciones Laborales, 26, núm. 1, pp. 89-122.

PRADOS DE REYES, F.J. (1991) "Representación unitaria y representación sindical en la empresa. Evolución de sistemas", Relaciones Laborales, 7, pp. 181-199. 
Prieto Rodríguez, C. (2001) "Trabajo y globalización económica". Globalización, trabajo y movimiento sindical. Madrid: Fundación Paz y Solidaridad, pp. 50-62.

QUINTANILla NAVARRO, B. (1999) Dimensión de la empresa y órganos de representación. Valencia: Tirant lo Blanch.

RIVERO LAMAS, J. (1997) "El empleo y las relaciones laborales en el umbral del siglo XXI", Temas Laborales, 44, pp. 3-26.

- (1998) "Los sindicatos y las asociaciones empresariales veinte años después de la Constitución", Revista del Ministerio de Trabajo y Asuntos Sociales, 13, pp. 157-198.

RODRíGUEZ ESCANCIANO, S. (2002) "Nuevos marcos para la acción colectiva: la implantación de un sistema de relaciones laborales más dinámico y participativo", Revista de Trabajo y Seguridad Social (Centro de Estudios Financieros), 235, pp. 3-60.

ROdRíGUEZ FERNÁNDEZ, M.L. (2004) "Participación sindical". R. EsCUdero RODRÍGUEZ (coord.) La negociación colectiva en España: una visión cualitativa. Valencia: Tirant lo Blanch, pp. 805-858.

RODRÍGUEZ-PIÑERO Y BRAVO-FERRER, M. (1981) "Las relaciones laborales en la España de los ochenta: la participación de los trabajadores en la empresa". Participación de los trabajadores en las decisiones de la empresa. Madrid: Organización Internacional del Trabajo, pp. 59-70.

- (1985) "La estructura y el funcionamiento democrático de los sindicatos", Revista de la Facultad de Derecho de la Universidad Complutense de Madrid, 7, pp. 161-178.

- (1985) "La Ley Orgánica de Libertad Sindical", Relaciones Laborales, 9, pp. 23-32.

- (coord.) (1986) Comentarios a la Ley de Libertad Sindical. Madrid: Tecnos.

- (1986) "La doble cara de las elecciones 'sindicales"', Relaciones Laborales, 10, pp. 27-35.

- (1991) "El sindicalismo de los años 90", VIII Jornadas Universitarias Andaluzas de Derecho del Trabajo y Relaciones Laborales. Sevilla: Consejo Andaluz de Relaciones Laborales, pp. 25-48.

- (1995) "Diálogo social, participación y negociación colectiva", Relaciones Laborales, 23, pp. 93-101.

RodRíGUEZ-SAÑUdO GUTIÉRREZ, F. (1986) "La representatividad sindical". M. RODRíGUEZ-PIÑERO Y BRAVO-FERRER (coord.) Comentarios a la Ley de Libertad Sindical. Madrid: Tecnos, pp. 189-217. 
ROMAGNOLI, U. (2001) "Redefinir las relaciones entre trabajo y ciudadanía: el pensamiento de Massimo D'Antona". J. LóPEZ LóPEZ (coord.) Nuevos escenarios para el Derecho del Trabajo: familia, inmigración y noción de trabajador. Homenaje a Massimo D'Antona. Madrid: Marcial Pons, pp. 309-323.

SAGARDOY BENGOECHEA, J.A. (2004) Las relaciones laborales en España, 1973-2003. Madrid: Cinca.

- y F. DURÁn LóPEZ (1984) El Proyecto de Ley Orgánica de Libertad Sindical. Madrid: Instituto de Estudios Económicos.

SANGUINETI RAYMOND, W. (1999) "Libertad sindical y rol institucional de los sindicatos: anotaciones a dos décadas de vigencia del texto constitucional", Revista de Derecho Social, 8, pp. 35-60.

SASTRE IBARRECHE, R. (2003) "Algunas claves para un sindicalismo también mundializado", Revista de Derecho Social, 21, pp. 67-96.

SeRna ARENILLAS, C. de la (2003) "Retos sindicales ante el siglo XXI", Revista de la Asociación Estatal de Centros Universitarios de Relaciones Laborales y Ciencias del Trabajo, 12, pp. 149-160.

SIMÓN, H.J. (2003) "¿Qué determina la afiliación a los sindicatos en España?", Revista del Ministerio de Trabajo y Asuntos Sociales, 41, pp. 69-88.

SCHMITTER, P.C. (1991) "La concertación social en perspectiva comparada". A. ESPINA (coord.) Concentración social, neocorporatismo y democracia. Madrid: Ministerio de Trabajo y Seguridad Social, pp. 67-80.

Sото RIOJA, S. de (2001) "El Derecho del Trabajo: entre la unidad y la fragmentación", Temas Laborales, 60, pp. 33-76.

SUÁREZ GONZÁLEZ, F. (1990) "La situación sindical en España". Los sindicatos en la sociedad industrial desarrollada. Madrid: Universidad Complutense, pp. 52-70.

SUPIOT, A. (coord.) (1999) Trabajo y empleo. Transformaciones del trabajo y futuro del Derecho del Trabajo en Europa. Valencia: Tirant lo Blanch.

- (1999) "Transformation du travail et devenir du Droit du Travail en Europe", Droit Social, 5, pp. 435-438.

TREU, T. (1988) "Innovazione e regole della rappresentanza sindacale", Lavoro e Diritto, 2, pp. 224-230.

VALDÉs DAL-RÉ, F. (1988) "Representación y representatividad sindicales en España", Relaciones Laborales, T. II, pp. 145-158.

- (dir.) (1994) La reforma del mercado laboral. Valladolid: Lex Nova. 
- (coord.) (1994) Sindicalismo y cambios sociales. Madrid: Consejo Económico y Social.

- (1996) "El sistema español de relaciones laborales: una aproximación", Relaciones Laborales, 1-2, pp. 117-154.

- (2003) "Transformaciones del Derecho del Trabajo y orden económico globalizado", Revista de la Asociación Estatal de Centros Universitarios de Relaciones Laborales y Ciencias del Trabajo, 12, pp. 131-148. 